\title{
Standard Operating Procedure
}

(SOP)

\begin{tabular}{|l|r|r|}
\hline Version: & $\# 1$ & \\
\hline $\begin{array}{l}\text { Issue/Revision } \\
\text { approved on: }\end{array}$ & 17.04 .2019 & $\begin{array}{r}\text { Experimental determination of partition constants } \\
\text { using C18-coated SPME fibres }\end{array}$ \\
\hline $\begin{array}{l}\text { Issue/Revision } \\
\text { approved by: }\end{array}$ & $\begin{array}{r}\text { Marie } \\
\text { Mühlenbrink }\end{array}$ & \\
\hline
\end{tabular}

\section{Training requirements}

- Introduction for the required devices (microbalance, $\mathrm{pH}$ meter, incubated orbital shaker, ultrasonic probe, centrifuge Heraeus Multifuge X1R)

- Introduction for the HPLC-UV/FLD system and the Triple Quad LC/MS system

\section{Safety warnings}

- Read and understand the risk assessment and MSDS (material safety data sheets) for ALL chemicals used!

- Always wear appropriate PPE (personal protective equipment). This includes (but is not limited to) a lab coat and nitrile gloves. The PPE required depends on the chemicals which will be used; please refer to the MSDS for additional PPE required.

- In case of chemical spills, refer to correct clean-up on MSDS.

- Clean the working space with isopropanol wipes when the work is done.

- Regarding the waste disposal follow the waste directives.

\section{Time requirements}

The experimental determination of partitioning of organic chemicals to biological material using C18-coated solidphase microextraction fibres can be divided into two phases - phase 1: method development and validation for the corresponding chemical, phase 2: application to biological material. The blue-coloured cells of the following table show the required days per week and experiment. Depending on the equilibration time of the chemicals for some experiments one more day is required (shaded blue-coloured cells).

\begin{tabular}{|c|c|c|c|c|c|}
\hline & & Day 1 & Day 2 & Day 3 & Day 4 \\
\hline \multirow{4}{*}{$\begin{array}{l}\text { Method } \\
\text { development }\end{array}$} & fibre uptake kinetics (c/t curves) & & & & \\
\hline & inter-fibre reproducibility & & & & \\
\hline & fibre sorption isotherm & & & & \\
\hline & cell culture basal media (OptiMEM/DMEM) & & & & \\
\hline \multirow{4}{*}{$\begin{array}{l}\text { Application } \\
\text { to biological } \\
\text { material }\end{array}$} & bovine serum albumin (BSA) & & & & \\
\hline & liposomes & & & & \\
\hline & fetal bovine serum (FBS) sorption isotherm & & & & \\
\hline & cell suspensions & & & & \\
\hline
\end{tabular}




\section{Table of Contents}

Experimental determination of partition constants using C18-coated SPME fibres ........................................

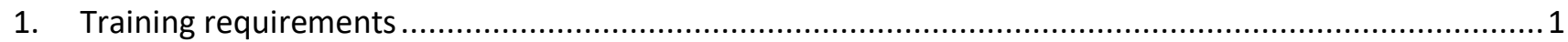

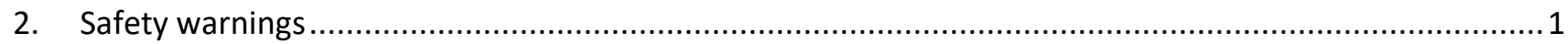

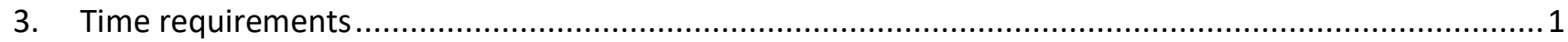

4. Determination of binding constants for neutral and ionizable chemicals using C18-coated SPME fibres ..3

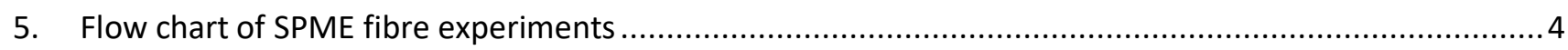

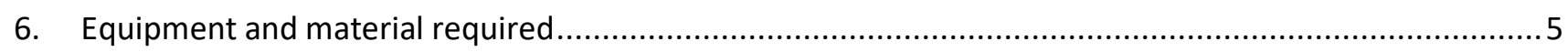

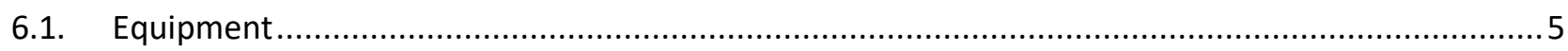

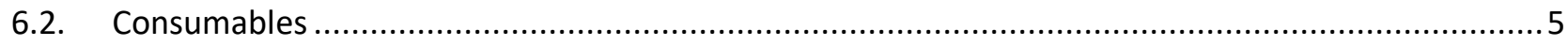

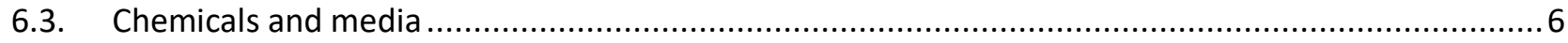

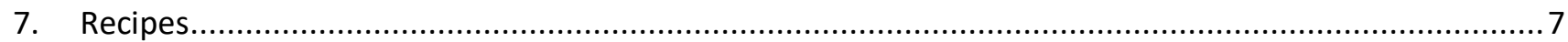

7.1. Preparation of $1 x$ Phosphate buffered saline (PBS) (pH 7.4) for SPME ..................................... 7

7.2. Preparation of cell culture basal media buffered with $10 \mathrm{mM} 3-(\mathrm{N}-$ Morpholino)propane-sulfonic

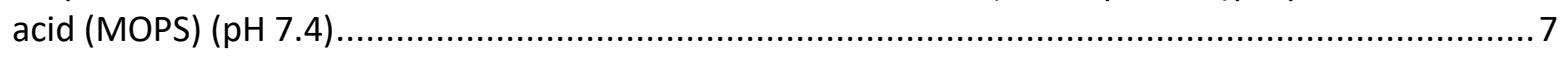

7.3. Preparation of bovine serum albumin (BSA) solution ........................................................

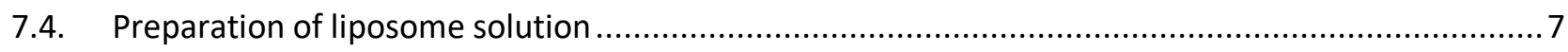

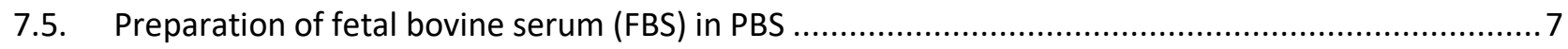

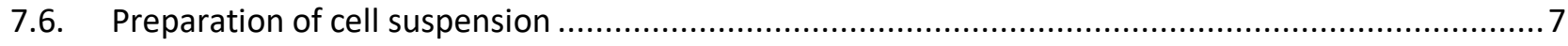

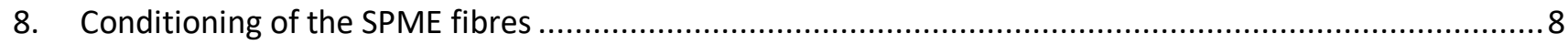

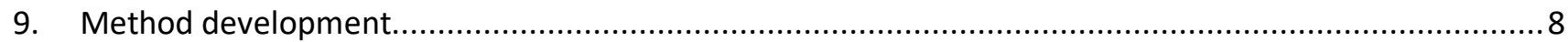

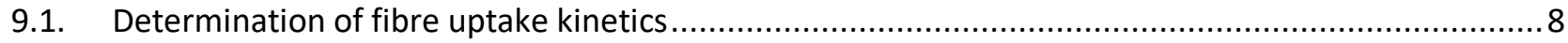

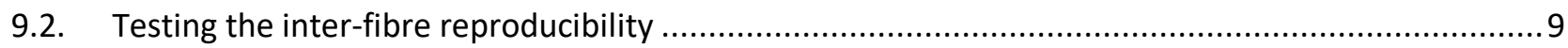

9.3. Testing the concentration dependence by measuring fibre sorption isotherms .............................9

9.4. Testing the partitioning to cell culture basal media buffered with $10 \mathrm{mM} 3$-(N-Morpholino)propane-

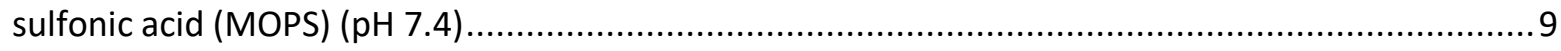

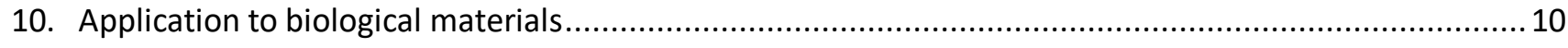

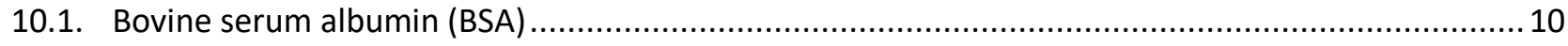

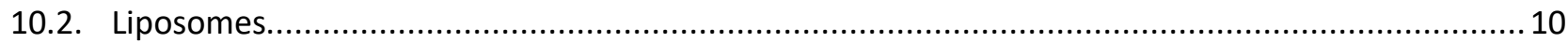

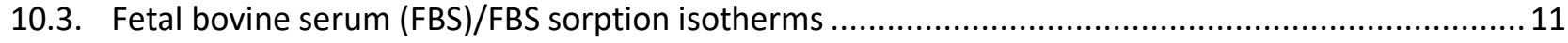

10.4. Homogenized suspensions of different cell lines .................................................................... 11

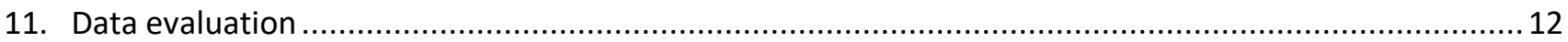

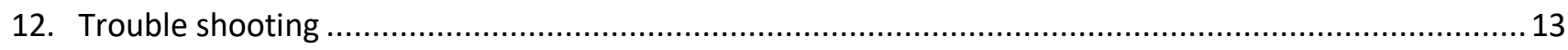

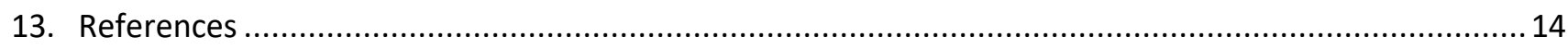




\section{Determination of binding constants for neutral and ionizable chemicals using C18-coated SPME fibres}

C18-coated SPME fibres appear to be an appropriate method to determine the binding constants for organic chemicals with various structures. Hydrophobic interactions with the C18 material and adsorption to the high surface area of the C18 particles (Figure 4) enable the sorption of neutral as well as ionizable chemicals [1]. By means of solvents like methanol or acetonitrile the chemicals can be easily desorbed. This technique only requires small sample volumes, reduces the use of solvents and removes biological matrices that disturb instrumental analysis. Since the SPME fibres have been especially designed for concentration measurements in biological samples they are chemically and mechanically stable and biocompatible. This means no fouling with proteins and lipids is expected [1].
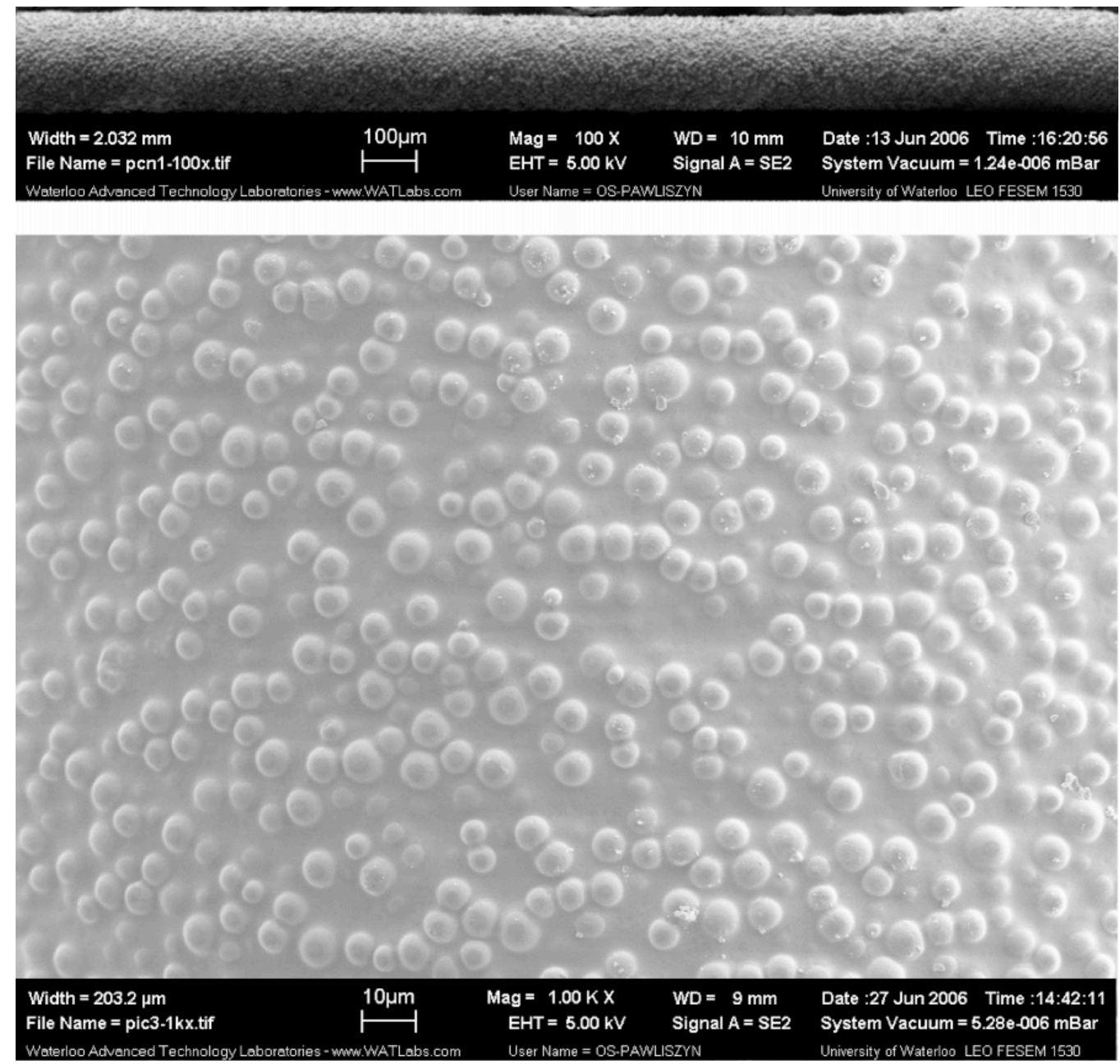

Figure 1: SEM images of PAN/C18 coatings at 100x and 1000x magnification.[2] Reprinted with permission from Musteata, M. L.; Musteata, F. M.; Pawliszyn, J. (2007): Biocompatible Solid-Phase Microextraction Coatings Based on Polyacrylonitrile and Solid-Phase Extraction Phases. Anal. Chem., 79: 6903-6911. Copyright 2007 American Chemical Society. 
5. Flow chart of SPME fibre experiments

\section{SPME fibre experiments}

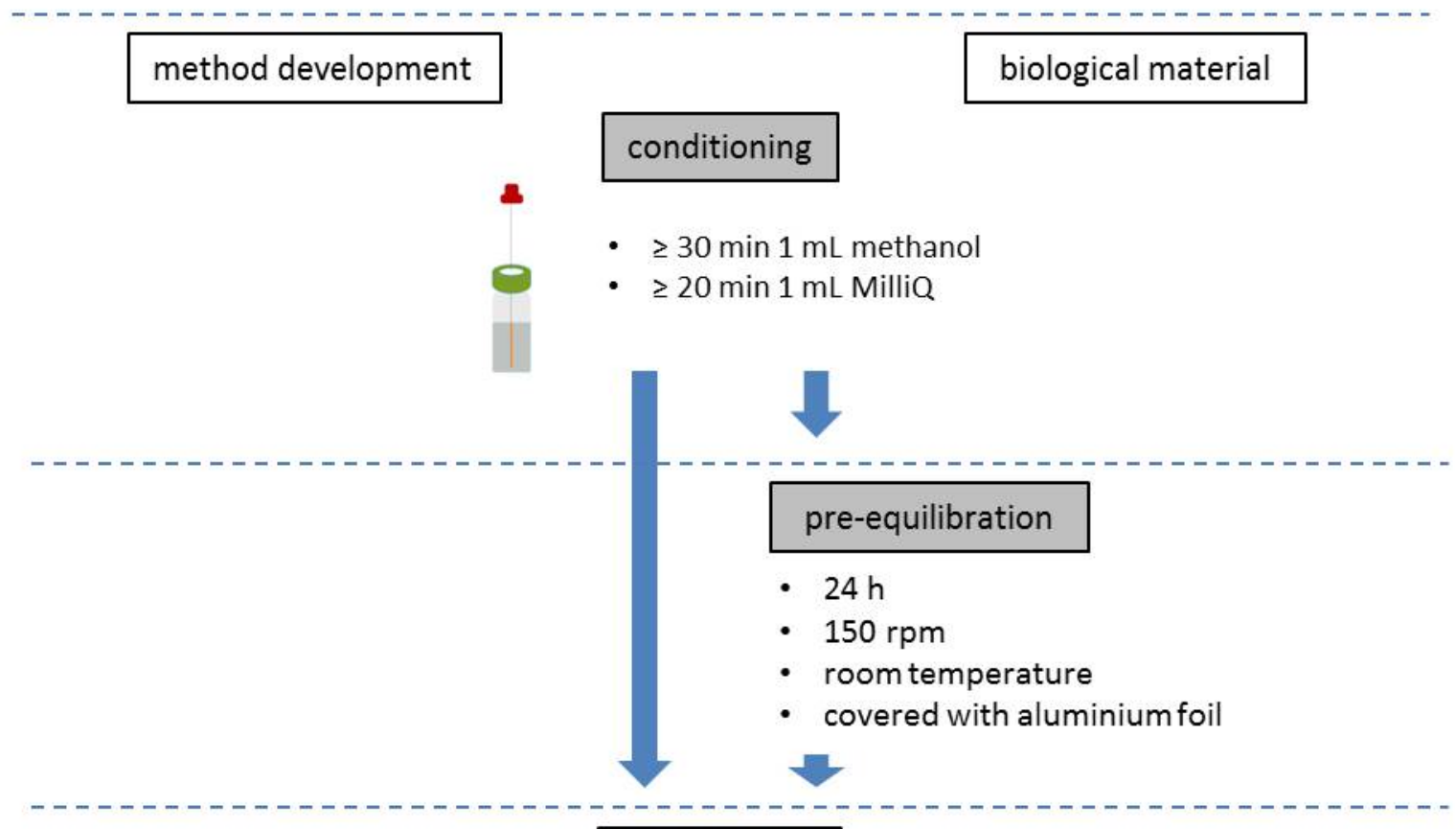

fibre loading

- sample volume: $\mathbf{1} \mathbf{~ m L}$ in $1.5 \mathrm{~mL}$ amber vials

- temperature: $37{ }^{\circ} \mathrm{C}$

- revolutions: $250 \mathrm{rpm}$

- very hydrophobic chemicals: $10 \mathrm{~mL}, 1200 \mathrm{rpm}$, NO PLASTIC

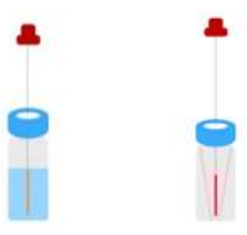

- sample volume: $1 \mathrm{~mL}$ in $1.5 \mathrm{~mL}$ amber vials or $\mathbf{1 8 0} \mu \mathrm{l} / \mathbf{2 0 0} \mu \mathrm{L}$ in $1.5 \mathrm{~mL}$ amber vials with inserts

- temperature: $37^{\circ} \mathrm{C}$

- revolutions: $250 \mathrm{rpm}$

- very hydrophobic chemicals: $10 \mathrm{~mL}, 1200 \mathrm{rpm}$, NO PLASTIC

Equilibration time depends on the chemical and has to be determined by measuring fibre uptake kinetics

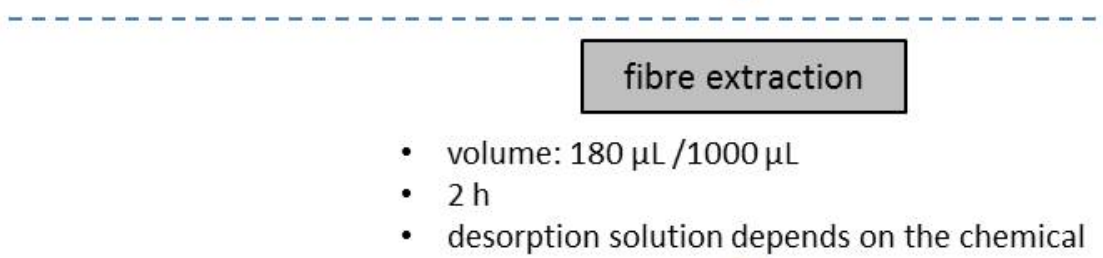

- desorption solution depends on the chemical

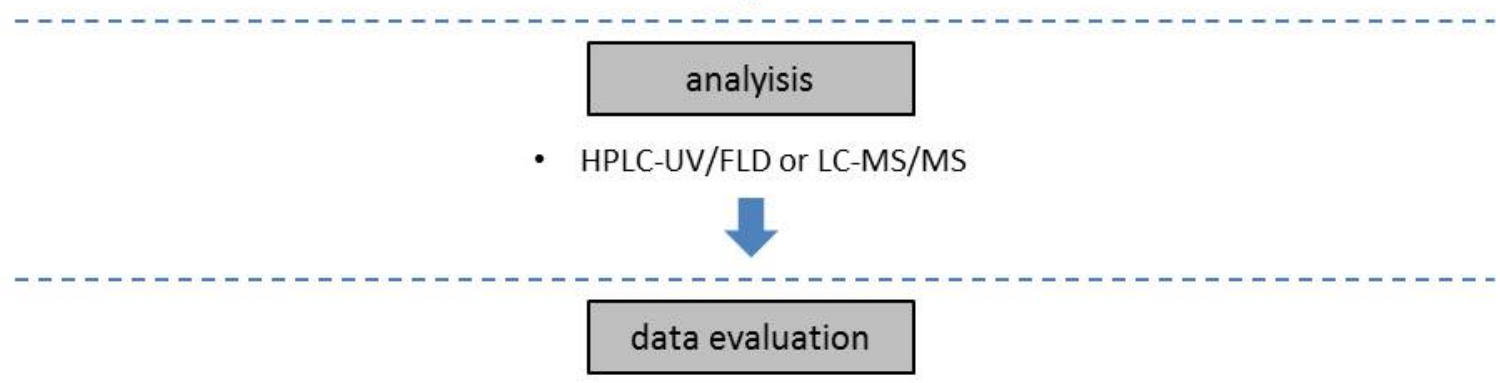




\section{Equipment and material required}

\subsection{Equipment}

- micro-analytical balance

- analytical balance

- ultrasonic water bath

- pipettes

- analytical syringe - eVol

- Multipette E3 (single channel)

- Schott flasks

- beakers

- volumetric flasks

- $\mathrm{pH}$ meter

- magnetic stirrer

- vortex mixer

- ultrasound probe

- centrifuge Heraeus Multifuge X1R

- fume hood

- incubated orbital shaker MaxQ 6000

- orbital shaker MaxQ 2000

- high-speed microplate shaker

- HPLC-UV/FLD system

- LC-MS/MS system

- tray, holding $54 \times 2 \mathrm{~mL}$ vials

- isopropanol wipes

\subsection{Consumables}

\begin{tabular}{|l|l|l|}
\cline { 2 - 3 } \multicolumn{1}{l|}{} & $\begin{array}{l}\text { Recommended } \\
\text { source }\end{array}$ & Cat. No. \\
\hline Nitrile gloves & & \\
\hline $\begin{array}{l}\text { Pipet tips }-0.1-10 \mu \mathrm{L}, 2-200 \mu \mathrm{L}, 50-1000 \mu \mathrm{L}, 100-5000 \mu \mathrm{L} \text { (with } \\
\text { dualfilter) }\end{array}$ & & \\
\hline glass Pasteur pipettes & & 0030089405 \\
\hline & & 0030089413 \\
& & 0030089430 \\
Combitips ${ }^{\circledR}$ advanced 0.1 $\mathrm{mL}, 0.2 \mathrm{~mL}, 1 \mathrm{~mL}, 2.5 \mathrm{~mL}, 5 \mathrm{~mL}, 10 \mathrm{~mL}, 25$ & Eppendorf & 0030089448 \\
$\mathrm{~mL}, 50 \mathrm{~mL}$ & & 0030089456 \\
& & 0030089464 \\
\hline $1.5 \mathrm{~mL}$ short thread vials ND 9, amber glass, wide opening & & 0030089472 \\
\hline
\end{tabular}




\begin{tabular}{|c|c|c|}
\hline & $\begin{array}{l}\text { Recommended } \\
\text { source }\end{array}$ & Cat. No. \\
\hline \multicolumn{3}{|l|}{$\begin{array}{l}1.5 \mathrm{~mL} \text { short thread vials ND 9, amber glass, wide opening, with } \\
\text { integrated micro-insert }\end{array}$} \\
\hline \multicolumn{3}{|l|}{ short thread screw caps ND9 with silicone/PTFE septa } \\
\hline $\begin{array}{l}\text { Solid-phase microextraction LC fibre probes, PAN/C18 coating, } \\
\text { coating thickness } 45 \mu \mathrm{m} \text {, coating length } 1.5 \mathrm{~cm} \text {, costumer specific }\end{array}$ & \multirow{3}{*}{$\begin{array}{l}\text { Sigma-Aldrich, } \\
\text { customized } \\
\text { product }\end{array}$} & \multirow{3}{*}{$57281-U$} \\
\hline $\begin{array}{l}\text { Solid-phase microextraction LC fibre probes, PAN/C18 coating, } \\
\text { coating thickness } 45 \mu \mathrm{m} \text {, coating length } 0.5 \mathrm{~cm} \text {, costumer specific }\end{array}$ & & \\
\hline $\begin{array}{l}\text { Solid-phase microextraction LC fibre probes, PAN/C18 coating, } \\
\text { coating thickness } 45 \mu \mathrm{m} \text {, coating length } 0.2 \mathrm{~cm} \text {, costumer specific }\end{array}$ & & \\
\hline Blunt cannulas $(0.8 \times 22 \mathrm{~mm})$, Sterican & Braun & 9180109 \\
\hline \multicolumn{3}{|l|}{$10 \mathrm{~mL}$ vials ND 24, amber glass } \\
\hline \multicolumn{3}{|l|}{ caps ND24 with silicone/PTFE septa } \\
\hline \multicolumn{3}{|l|}{ crimp neck vials ND 11, amber glass, wide opening } \\
\hline \multicolumn{3}{|l|}{$\begin{array}{l}\text { crimp neck vials ND 11, amber glass, wide opening, with integrated } \\
\text { micro-insert }\end{array}$} \\
\hline \multicolumn{3}{|l|}{$\begin{array}{l}\text { aluminium crimp cap ND 11, center hole with O-ring and } \\
\text { aluminium septa TPF }\end{array}$} \\
\hline \multicolumn{3}{|l|}{$10 \mathrm{~mL}$ crimp neck and headspace vials ND20, amber glass } \\
\hline crimp and headspace caps ND20 with PTFE/aluminium septa & & \\
\hline
\end{tabular}

\subsection{Chemicals and media}

\begin{tabular}{|l|l|l|}
\cline { 2 - 3 } \multicolumn{1}{l|}{} & $\begin{array}{l}\text { Recommended } \\
\text { source }\end{array}$ & Cat. No. \\
\hline methanol, gradient grade, for HPLC, $\geq 99.9 \%$ & & \\
\hline acetonitrile, gradient grade, for HPLC, $\geq 99.9 \%$ & & \\
\hline 2-propanol, gradient grade, for HPLC & & \\
\hline compounds for preparation of PBS (Phosphate Buffered Saline) & & A7030 \\
\hline $\begin{array}{l}\text { Bovine Serum Albumin, heat shock fraction, protease free, fatty acid free, } \\
\text { essentially globulin free, pH 7, } \geq 98 \% \text { (Sigma-Aldrich) }\end{array}$ & Sigma-Aldrich & \\
\hline MOPS (3-(N-Morpholino)propane-sulfonic acid) & & $31966-021$ \\
\hline DMEM, high glucose, GlutaMAX'M Supplement, pyruvate & Gibco & $31053-028$ \\
\hline Opti-MEM ${ }^{\circledR}$ I Reduced Serum Medium, no phenol red & Gibco & $10099-141$ \\
\hline Fetal Bovine Serum, qualified, Australia origin & Gibco & \\
\hline compounds for preparation of liposomes & & \\
\hline cells (HepG2, HEK293T etc.) & & \\
\hline
\end{tabular}




\section{Recipes}

\subsection{Preparation of 1x Phosphate buffered saline (PBS) (pH 7.4) for SPME}

1. Prepare 10x PBS solution

2. Preparation of $1 \times$ PBS

a. Measure out $100 \mathrm{~mL}$ of $10 x$ PBS in measuring cylinder

b. Fill up with MilliQ water to $1 \mathrm{~L}$

c. Adjust $\mathrm{pH}$ to 7.4 using $10 \mathrm{M} \mathrm{HCl}$ or $2 \mathrm{~N} \mathrm{NaOH}$

\subsection{Preparation of cell culture basal media buffered with $10 \mathrm{mM}$ 3-(N-Morpholino)propane- sulfonic acid (MOPS) (pH 7.4)}

1. Weigh $104.6 \mathrm{mg}$ MOPS into a $50 \mathrm{~mL}$ beaker using an analytical balance

2. Dissolve the MOPS in $45 \mathrm{~mL}$ cell culture basal medium (OptiMEM or DMEM)

3. Adjust the $\mathrm{pH}$ to 7.4

4. Transfer to a $50 \mathrm{~mL}$ volumetric flask and fill up to the mark

\subsection{Preparation of bovine serum albumin (BSA) solution}

1. Weigh required amount (e.g., $100 \mathrm{mg}$ for a solution with $10 \mathrm{mg} / \mathrm{mL}$ ) of $B S A$ onto a plastic weighing boat using the micro-analytical balance and an antistatic plastic spatula

2. Transfer to a plastic volumetric flask (e.g., $10 \mathrm{~mL}$ ) and rinse the weighing boat with $1 \times \mathrm{PBS}(\mathrm{pH} 7.4)$

3. Either fill up to the mark with $1 \times \mathrm{PBS}(\mathrm{pH} 7.4)$ or add the chemical first to the volumetric flask and then fill it up to the mark

\subsection{Preparation of liposome solution}

see reference [1] and [3]

\subsection{Preparation of fetal bovine serum (FBS) in PBS}

1. For a $10 \%$ FBS solution add $1 \mathrm{~mL}$ of FBS to a $10 \mathrm{~mL}$ volumetric flask and fill up to the mark with $1 \times$ PBS

2. Adjust $\mathrm{pH}$ to 7.4 using $10 \mathrm{M} \mathrm{HCl}$ or $2 \mathrm{~N} \mathrm{NaOH}$

\subsection{Preparation of cell suspension}

1. Resuspend the cell pellet in $1 \mathrm{~mL} 1 \times \mathrm{PBS}(\mathrm{pH} 7.4)$

(Depending on the cell number the cells may have a notable influence on the total volume. In this case use a $1 \mathrm{~mL}$ volumetric flask.)

2. Use an ultrasound probe $(9 * 10 \%$ cycles, $2 \times 30 \mathrm{sec})$ for the homogenization of the cells. Put the tubes on ice in between.

3. If foam has formed, centrifuge the cell suspension ( $2 \times 1 \mathrm{~min}, 500 \mathrm{rpm})$

4. Store the suspension on ice until usage (same day!) 


\section{Conditioning of the SPME fibres}

1. Use blunt cannulas to safely transfer the SPME fibres to the conditioning vials and the samples.

2. Prepare $20 \mathrm{~mL}$ amber glass vials with methanol or MilliQ. $(1 \times 20 \mathrm{~mL}$ vial for 12 SPME fibres)

3. Pierce the silicone/PTFE septum of the caps with the fibres by means of the blunt cannulas

4. Condition the SPME fibres in methanol for at least $2 \mathrm{~h}$ and subsequently at least $30 \mathrm{~min}$ in MilliQ before each experiment.

5. Store the fibres in a mixture of methanol and water (50:50) after the experiment

Once conditioned, the fibres should be quickly transferred to the sample to avoid drying of the coating. Otherwise the sorption capacity of the fibres could be reduced and the variability of the fibre concentration could be increased.

Furthermore, check the fibre coating for damages before each experiment. If necessary, clean the SPME fibres with isopropanol wipes (especially after using the fibres with lipid-rich samples).

\section{Method development}

\subsection{Determination of fibre uptake kinetics}

1. Prepare stock solutions of the test chemicals in methanol. Store at $-20^{\circ} \mathrm{C}$ for up to six months.

2. Prepare samples by spiking the stock solution to $1 \times$ PBS (pH 7.4).

The methanol content should be $<1 \%$.

a. Prepare replicates of the PBS solution of the test chemical (volume $1 \mathrm{~mL}$ in $1.5 \mathrm{~mL}$ amber glass vials). Suggested time points for the determination of the equilibration time: $15 \mathrm{~min}, 30 \mathrm{~min}$, $1 \mathrm{~h}, 2 \mathrm{~h}, 4 \mathrm{~h}, 6 \mathrm{~h}, 24 \mathrm{~h}$ and $48 \mathrm{~h}$.

b. Prepare at least two replicates for each time point.

c. Prepare control samples without fibres. Incubate $1 \mathrm{x}$ control sample at $4^{\circ} \mathrm{C}$ (fridge) for $48 \mathrm{~h}$ and $1 \mathrm{x}$ control sample at $37^{\circ} \mathrm{C}$ for $48 \mathrm{~h}$.

3. Incubate the samples at $37^{\circ} \mathrm{C}$ and under slight shaking $(250 \mathrm{rpm})$ using the orbital shaker MaxQ 6000 .

a. In case of hydrophobic chemicals use the high-speed microplate shaker (set to $1200 \mathrm{rpm}$ ), crimp vials and aluminium crimp caps. No Plastic! Use fibres without handle and cannulas!

b. Protect the samples from light.

4. Transfer the fibres to vials with fused-in inserts with $180 \mu \mathrm{L}$ (or normal vials with $1 \mathrm{~mL}$ ) of desorption solution to extract the test chemical for at least $2 \mathrm{~h}$.

a. Check which desorption solution works best (e.g., acetonitrile and water (90:10) for moderately hydrophobic chemicals, acetonitrile and water (10:90) for hydrophilic compounds, methanol and water (50:50) for organic acids or $100 \%$ acetonitrile for hydrophobic compounds)

5. Analyse the PBS samples and the extracts by HPLC-UV/FLD or LC-MS/MS. 


\subsection{Testing the inter-fibre reproducibility}

1. Prepare stock solutions of the test chemicals in methanol or use one that is already prepared.

2. Prepare samples by spiking the stock solution to $1 \mathrm{x} \mathrm{PBS}(\mathrm{pH} 7.4)$.

The methanol content should be $<1 \%$.

a. Prepare 10 replicates of the test chemical (volume $1 \mathrm{~mL}$ in $1.5 \mathrm{~mL}$ amber glass vials) in $1 \times$ PBS (pH 7.4). The sample volume can be increased to $10 \mathrm{~mL}$ for hydrophobic chemicals with poor water solubility. Prevent use of plastic in case of hydrophobic test chemicals.

b. Prepare one control sample without a fibre.

3. Incubate the samples at $37^{\circ} \mathrm{C}$ and under slight shaking $(250 \mathrm{rpm})$ using the orbital shaker MaxQ 6000.

a. In case of hydrophobic chemicals use the high-speed microplate shaker (set to $1200 \mathrm{rpm}$ ), crimp vials and aluminium crimp caps. No Plastic! Use fibres without handle and cannulas!

b. Protect the samples from light.

4. Transfer the fibres to vials with fused-in inserts with $180 \mu \mathrm{L}$ (or normal vials with $1 \mathrm{~mL}$ ) of desorption solution to extract the test chemical for at least $2 \mathrm{~h}$.

5. Analyse the PBS samples and the extracts by HPLC-UV/FLD or LC-MS/MS.

\subsection{Testing the concentration dependence by measuring fibre sorption isotherms}

1. Prepare stock solutions of the test chemicals in methanol or use one that is already prepared.

2. Prepare samples by spiking the stock solution to $1 \times \mathrm{PBS}(\mathrm{pH} 7.4)$.

The methanol content should be $<1 \%$.

a. Prepare samples with several concentration levels of the test chemical over 3 orders of magnitude (volume $1 \mathrm{~mL}$ in $1.5 \mathrm{~mL}$ amber glass vials) and triplicates for each concentration level. The sample volume can be increased to $10 \mathrm{~mL}$ for hydrophobic chemicals with poor water solubility. Prevent use of plastic in case of hydrophobic test chemicals.

b. Prepare one control for each concentration level without a fibre.

3. Incubate the samples at $37^{\circ} \mathrm{C}$ and under slight shaking $(250 \mathrm{rpm})$ using the orbital shaker MaxQ 6000 .

a. In case of hydrophobic chemicals use the high-speed microplate shaker (set to $1200 \mathrm{rpm}$ ), crimp vials and aluminium crimp caps. No Plastic! Use fibres without handle and cannulas!

b. Protect the samples from light.

4. Transfer the fibres to vials with fused-in inserts with $180 \mu \mathrm{L}$ (or normal vials with $1 \mathrm{~mL}$ ) of desorption solution to extract the test chemical for at least $2 \mathrm{~h}$.

5. Analyse the PBS samples and the extracts by HPLC-UV/FLD or LC-MS/MS.

\subsection{Testing the partitioning to cell culture basal media buffered with $10 \mathrm{mM}$ 3-(N- Morpholino)propane-sulfonic acid (MOPS) (pH 7.4)}

1. Prepare stock solutions of the test chemicals in methanol or use one that is already prepared.

2. Prepare samples by spiking the stock solution to $1 \times \mathrm{PBS}(\mathrm{pH} 7.4)$ as well as OptiMEM and DMEM buffered with $10 \mathrm{mM}$ MOPS (pH 7.4) The methanol content should be $<1 \%$. 
a. Prepare triplicates of the test chemical (volume $1 \mathrm{~mL}$ in $1.5 \mathrm{~mL}$ amber glass vials) in $1 \mathrm{x}$ PBS (pH 7.4) as wells as in OptiMEM and DMEM buffered with $10 \mathrm{mM}$ MOPS (pH 7.4). The sample volume can be increased to $10 \mathrm{~mL}$ for hydrophobic chemicals with poor water solubility. Prevent use of plastic in case of hydrophobic test chemicals.

a. Prepare one control sample per medium without a fibre.

3. Incubate the samples at $37^{\circ} \mathrm{C}$ and under slight shaking $(250 \mathrm{rpm})$ using the orbital shaker MaxQ 6000 .

a. In case of hydrophobic chemicals use the high-speed microplate shaker (set to $1200 \mathrm{rpm}$ ), crimp vials and aluminium crimp caps. No Plastic! Use fibres without handle and cannulas!

b. Protect the samples from light.

4. Transfer the fibres to vials with fused-in inserts with $180 \mu \mathrm{L}$ (or normal vials with $1 \mathrm{~mL}$ ) of desorption solution to extract the test chemical for at least $2 \mathrm{~h}$.

5. Analyse the PBS samples and the extracts by HPLC-UV/FLD or LC-MS/MS.

\section{Application to biological materials}

\subsection{Bovine serum albumin (BSA)}

1. Prepare stock solutions of the test chemicals in methanol or use one that is already prepared.

2. Prepare samples by spiking the stock solution to $10 \mathrm{mg} / \mathrm{mL} \mathrm{BSA}$. The methanol content should be $<1 \%$.

a. Prepare 4 replicates of the test chemical (volume $1 \mathrm{~mL}$ in $1.5 \mathrm{~mL}$ amber glass vials) in $10 \mathrm{mg} / \mathrm{mL}$ BSA. If high/low sorption to BSA is expected, decrease/increase the BSA concentration. Please note that BSA may adsorb to glassware. Do not use BSA concentrations $<1 \mathrm{mg} / \mathrm{mL}$.

b. Prepare duplicates of the test chemical in $1 \times$ PBS ( $\mathrm{pH} 7.4)$ as control samples with fibres.

3. Incubate the samples at $37^{\circ} \mathrm{C}$ and under slight shaking $(250 \mathrm{rpm})$ using the orbital shaker MaxQ 6000 .

a. In case of hydrophobic chemicals use the high-speed microplate shaker (set to $1200 \mathrm{rpm}$ ), crimp vials and aluminium crimp caps. No Plastic! Use fibres without handle and cannulas!

b. Protect the samples from light.

4. Transfer the fibres to vials with fused-in inserts with $180 \mu \mathrm{L}$ (or normal vials with $1 \mathrm{~mL}$ ) of desorption solution to extract the test chemical for at least $2 \mathrm{~h}$.

5. Analyse the PBS control samples and all extracts (BSA and PBS extracts) by HPLC-UV/FLD or LC-MS/MS.

\subsection{Liposomes}

1. Prepare stock solutions of the test chemicals in methanol or use one that is already prepared.

2. Prepare samples by spiking the stock solution to $10 \mathrm{mg} / \mathrm{mL}$ liposomes.

The methanol content should be $<1 \%$.

a. Prepare samples with 3 different concentrations of the test chemical over at least 2 orders of magnitude (volume $180 \mu \mathrm{L}$ in $1.5 \mathrm{~mL}$ amber glass vials with fused-in inserts) and 4 replicates for each concentration level. If high/low sorption to liposomes is expected, decrease/increase the liposome concentration. The sample volume can be increased to 1-10 $\mathrm{mL}$ for hydrophobic chemicals with poor water solubility. Prevent use of plastic in case of hydrophobic test chemicals. 
b. Prepare control samples in $1 \times$ PBS ( $\mathrm{pH} 7.4$ ) with 3 different concentrations of the test chemical and duplicates for each concentration level. The extract concentration of the controls should be as high as the extract concentration of the liposome samples.

3. Incubate the samples at $37^{\circ} \mathrm{C}$ and under slight shaking $(250 \mathrm{rpm})$ using the orbital shaker MaxQ 6000 .

a. In case of hydrophobic chemicals use the high-speed microplate shaker (set to $1200 \mathrm{rpm}$ ), crimp vials and aluminium crimp caps. No Plastic! Use fibres without handle and cannulas!

b. Protect the samples from light.

4. Transfer the fibres to vials with fused-in inserts with $180 \mu \mathrm{L}$ (or normal vials with $1 \mathrm{~mL}$ ) of desorption solution to extract the test chemical for at least $2 \mathrm{~h}$.

5. Analyse the PBS control samples and all extracts (liposome and PBS extracts) by HPLC-UV/FLD or LCMS/MS.

\subsection{Fetal bovine serum (FBS)/FBS sorption isotherms}

1. Prepare stock solutions of the test chemicals in methanol or use one that is already prepared.

2. Prepare samples by spiking the stock solution to $10 \%$ FBS in PBS.

The methanol content should be $<1 \%$.

a. Prepare samples with at least 3 different concentrations of the test chemical over 2 orders of magnitude (volume $200 \mu \mathrm{L}$ in $1.5 \mathrm{~mL}$ amber glass vials with fused-in inserts) and $4 x$ replicates for each concentration level. If high/low sorption to FBS is expected, decrease/increase the FBS concentration. The sample volume can be increased to 1-10 $\mathrm{mL}$ for hydrophobic chemicals with poor water solubility. Prevent use of plastic in case of hydrophobic test chemicals.

b. Prepare control samples in $1 \times$ PBS (pH 7.4) with 3 different concentrations of the test chemical and duplicates for each concentration level. The extract concentration of the controls should be as high as the extract concentration of the FBS samples.

c. Prepare one control for each concentration level without a fibre.

3. Incubate the samples at $37^{\circ} \mathrm{C}$ and under slight shaking $(250 \mathrm{rpm})$ using the orbital shaker MaxQ 6000 .

a. In case of hydrophobic chemicals use the high-speed microplate shaker (set to $1200 \mathrm{rpm}$ ), crimp vials and aluminium crimp caps. No Plastic! Use fibres without handle and cannulas!

b. Protect the samples from light.

4. Transfer the fibres to vials with fused-in inserts with $180 \mu \mathrm{L}$ (or normal vials with $1 \mathrm{~mL}$ ) of desorption solution to extract the test chemical for at least $2 \mathrm{~h}$.

5. Analyse the PBS control samples and all extracts (FBS and PBS extracts) by HPLC-UV/FLD or LC-MS/MS.

\subsection{Homogenized suspensions of different cell lines}

1. Prepare stock solutions of the test chemicals in methanol or use one that is already prepared.

2. Prepare samples with homogenized suspensions of cell lines like HepG2, HEK293T etc. The methanol content should be $<1 \%$.

a. Prepare triplicates (volume $200 \mu \mathrm{L}$ in $1.5 \mathrm{~mL}$ amber glass vials with fused-in inserts). The required cell number per sample depends on the test chemical. The sample volume can be 
increased to 1-10 mL for hydrophobic chemicals with poor water solubility. Prevent use of plastic in case of hydrophobic test chemicals.

b. Prepare 4 replicates of the test chemical in $1 \times$ PBS (pH 7.4) as control samples with fibres.

3. Incubate the samples at $37^{\circ} \mathrm{C}$ and under slight shaking $(250 \mathrm{rpm})$ using the orbital shaker MaxQ 6000 .

a. In case of hydrophobic chemicals use the high-speed microplate shaker (set to $1200 \mathrm{rpm}$ ), crimp vials and aluminium crimp caps. No Plastic! Use fibres without handle and cannulas!

b. Protect the samples from light.

4. Transfer the fibres to vials with fused-in inserts with $180 \mu \mathrm{L}$ (or normal vials with $1 \mathrm{~mL}$ ) of desorption solution to extract the test chemical for at least $2 \mathrm{~h}$.

5. Analyse the PBS control samples and all extracts (cell suspension and PBS extracts) by HPLC-UV/FLD or LC-MS/MS.

\section{Data evaluation}

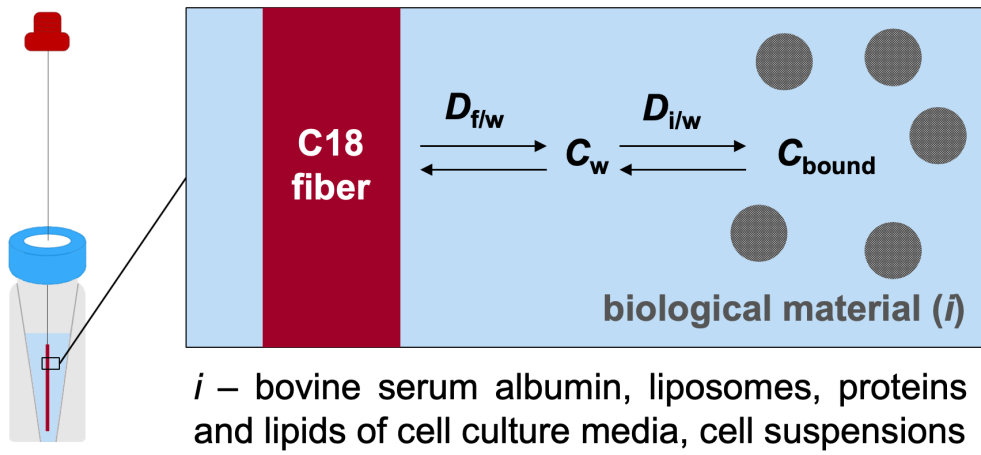

Figure 2: Partitioning processes [1]. Reprinted with permission from Henneberger, L.; Mühlenbrink, M; Fischer, F. C.; Escher, B. I. (2019): C18-Coated Solid-Phase Microextraction Fibers for the Quantification of Partitioning of Organic Acids to Proteins, Lipids, and Cells. Chem. Res. Toxicol., 32 (1): 168-178. Copyright 2018 American Chemical Society.

Fibre-water partitioning:

As described by Henneberger et al. 2019 the measured concentrations in the fibre extracts $\left(C_{\mathrm{ex}}\right)$, the volumes of desorption solution $\left(V_{\mathrm{ex}}\right)$ and fibre coating $\left(V_{\mathrm{f}}\right)$ are used to calculate the concentration of the test chemicals in the SPME fibre $\left(C_{f}\right)$ :

$\mathrm{C}_{\mathrm{f}}=\frac{\mathrm{C}_{\mathrm{ex}} \cdot \mathrm{V}_{\mathrm{ex}}}{\mathrm{V}_{\mathrm{f}}}$

eq.1

The measured fibre sorption isotherms are fitted using the log-transformed Freundlich model (eq. 2) to check linearity of sorption. Freundlich coefficient and Freundlich exponent are indicated by $K_{\mathrm{Fr}}$ and $n_{\mathrm{Fr}}$, respectively.

$\log C_{\mathrm{f}}=\log \mathrm{K}_{\mathrm{Fr}}+\mathrm{n}_{\mathrm{Fr}} \cdot \log \mathrm{C}_{\mathrm{w}}$

The fibre-water distribution ratio $\left(D_{\mathrm{f} / \mathrm{w}}\right)$ is calculated using eq. 3 .

$\mathrm{D}_{\mathrm{f} / \mathrm{w}}(\mathrm{pH} 7.4)\left[\mathrm{L}_{\mathrm{w}} / \mathrm{L}_{\mathrm{f}}\right]=\frac{\mathrm{C}_{\mathrm{f}}}{\mathrm{C}_{\mathrm{w}}}$ 
Partitioning to biological materials:

The calculation of the distribution ratios between the biological material and water $\left(D_{\mathrm{i} / \mathrm{w}}\right.$, i refers to BSA, liposomes or the sum of proteins and lipids in FBS) is based on the full mass balance, because negligible depletion conditions cannot be ensured in all experiments [1], [4].

In eq. $4, C_{\text {bound }}$ is the concentration of the test chemical bound to the total amount of proteins and lipids in the solution, $n_{\text {tot }}$ is the total amount of chemical added to the vial, $V_{w}$ is the volume of water, and $V_{i}$ is the total volume of proteins and lipids in the solution. $n_{\text {tot }}$ is defined as the sum of the amount of the test chemical in water, in fiber, and bound to the proteins and lipids ( $n_{\text {bound }}$ ).

$D_{i / w}(p H 7.4)\left[L_{w} / L_{i}\right]=\frac{C_{\text {bound }}}{C_{w}}=\frac{\frac{n_{t o t}}{n_{f}} \cdot D_{f / w} \cdot V_{f}-V_{w}-V_{f} \cdot D_{f / w}}{V_{i}}$

The distribution ratio between the cells and water $\left(D_{\text {cell }} / w\right)$ is based on the total cell volume and calculated according to eq. 5 :

$D_{\text {cell } / w}(p H 7.4)\left[L_{w} / k g_{i}\right]=\frac{C_{c e l l}}{C_{w}}=\frac{\frac{n_{t o t}}{n_{f}} \cdot D_{f / w} \cdot V_{f}-V_{w}-V_{f} \cdot D_{f / w}}{V_{\text {cell }}}$ eq.5

The concentration in the cells is indicated by $C_{\text {cell. }}$. The total volume of the cells in the vial $\left(V_{\text {cell }}\right)$ is required in eq. 5, but only the cell count of the suspensions before homogenization is known. Based on experimentally determined cellular volumes, the average cell count of $1 \mathrm{~L}$ of cells can be calculated for all cell lines. This factor can be used to convert the cell count of the cell suspensions to $V_{\text {cell. }}$ [1]

\section{Trouble shooting}

\section{Calculated mass balance from controls below $80 \%$}

- Check, if the test chemical sorbes to plastic or if it is volatile.

- Check, whether the extraction time was long enough and that an appropriate desorption solution was chosen.

- Check, the HPLC-UV/FLD or LC-MS/MS method, the signal intensity may depend on the type of solvent (e.g., acetonitrile vs. PBS samples). Especially in LC-MS/MS PBS can cause suppression of signal due to adduct formation.

\section{High variability and other measurement artefacts (e.g., experimental $C_{\text {free }}>C_{\text {nom }}$ )}

- Check the $\mathrm{pK}_{\mathrm{a}}$ of ionizable test chemicals and the $\mathrm{pH}$ of the tested samples. Make sure the $\mathrm{pH}$ is stable and close to the $\mathrm{pH}$ of the control samples.

- Once conditioned the fibre coating must not dry out. Transfer the fibres from one solution to the other as fast as possible. Drying of coating can lead to high variability in fibre concentrations.

\section{Too high or too low fraction bound to the biological material}

- Adjust the amount of the biological material to a fraction bound of $20-90 \%$ for a reliable data evaluation 


\section{References}

[1] Henneberger, L.; Mühlenbrink, M; Fischer, F. C.; Escher, B. I. (2019): C18-Coated Solid-Phase Microextraction Fibers for the Quantification of Partitioning of Organic Acids to Proteins, Lipids, and Cells. Chem. Res. Toxicol., 32 (1): 168-178

[2] Musteata, M. L.; Musteata, F. M.; Pawliszyn, J. (2007): Biocompatible Solid-Phase Microextraction Coatings Based on Polyacrylonitrile and Solid-Phase Extraction Phases. Anal. Chem., 79: 6903-6911

[3] Kaiser, S. M., and Escher, B. I. (2006) The Evaluation of Liposome-Water Partitioning of 8Hydroxyquinolines and Their Copper Complexes. Environmental Science \& Technology 40, 1784-1791.

[4] Neale, P. A.; Antony, A.; Gernjak, W.; Leslie, G.; and Escher, B. I. (2011): Natural versus wastewater derived dissolved organic carbon: Implications for the environmental fate of organic micropollutants. Water Res. 45: 4227-4237 